\title{
THE PATHOLOGY OF MYXEDEMA
}

\section{ILLUSTRATED IN A TYPICAL CASE.}

$\mathbf{B Y}$

JOHN HARLEY, M.D. LoND., F.R.C.P., IFCTURFR ON GENRRAT ANATOMY AND PHYSIOLOGY AND PHYGIOIAN TO BT. THOMAB'S HOSPITAI.

(Received February 12th-Read April 8th, 1884.)

IN his paper on this subject, published in the sixty-first volume of the 'Transactions' of this Society, Dr. Ord has given faithful reproductions of two photographs of Harriet Brown, one taken at the age of twenty-one when in a state of health, and the other at the age of twenty-seven when the subject of fully-developed myxœdema. She came under my care about three years before she was brought under the notice of this Society in 1877, and continued so up to the time of her death in 1881, and was regarded at St. Thomas's as a typical example of myxœdema. As I am now able to give a complete account of her case, I think it will prove interesting as a supplement to Dr. Ord's paper, and as an aid in the elucidation of this morbid condition.

At the age of twenty-one $\mathrm{H}$. B- was a bright, active, slender woman, about $5 \mathrm{ft} .3 \mathrm{in}$. in height, and weighing 
between eight and nine stone, of fair skin and dark hair. She had always enjoyed good health, there was no remembrance of any particular disorder in infancy, and she never had scarlet fever. Her general appearance at this time is given in $\mathrm{Pl}$. vii, fig. 1, vol. lxi of the ' Transactione.'

Her parents, a sister, and two brothers are still alive, strong, and healthy. Her second and last child (who is now a bright, lively, spare, and healthy little girl) was born in 1871, at which time the patient was twenty-six years old.

The disease undoubtedly had its origin at this puerperal period. ${ }^{1}$ The labour was not a good one, and recovery. was protracted and imperfect. A year afterwards the myxœdema was fully developed, as will be seen in fig. 2 of the plate just referred to.

Three years later she came under my notice, and for the next five years, i.e. up to 1879 , there was no noteworthy change in her condition. She merely complained of debility. The integument of the face was thickened, the eyelids puffy, and the bright crimson injection of the fair cheeks contrasted with the very dark brown hair. Excepting an occasional slight pitting over the tibiæ, and a little puffiness of the ankles, there was no thickening or œdema of the legs. All the functions were normally performed. The urine was frequently examined, and always found of rather low specific gravity and free from albumen. The pelvic and abdominal viscera were healthy.

The only defects discernible were deficient expansion of the chest walls with slightly prolonged expiration and impaired resonance-the usual indications of chronic pleuritic adhesions-and a rather feeble ventricular contraction. The pulse was correspondingly weak, but otherwise quite normal.

She took chalybeate tonics with advantage, and was always able to attend to her household duties.

Becoming a little weaker she was admitted into Christian Ward on 2nd September, 1879, and remained

1 See p. 194. 
in the hospital fourteen weeks. She said that three weeks previously she was suddenly taken with giddiness and weakness in the left side, and she should have fallen but for help.

The following was her condition at this time:-She was fairly well nourished, complained of increased weakness, of pain in the back of the head and down the back, of impairment of memory and of vision of the left eye. Excepting a little weakness of the left leg there was no special diminution of muscular power, nor was there any sign of nerve lesion or disorder. There was a little cough at night, a few bronchitic râles in the right lung, and a little crackling and diminished resonance at the left base posteriorly. The apex beat of the heart was neither visible nor palpable, but the position and sounds were normal; the pulse 72, weak. Both flanks were rather dull, but the abdomen was otherwise normal. There was slight œdema over the shins, and the feet became a little puffy on standing. The urine was normal and averaged about forty-eight ounces.

From the 9th to the 12th September the arine decreased to fourteen, twelve, and four ounces in the twenty-four hours, but continued normal ; the puffiness of the face and œdema of the feet increased, the skin was moist, pulse 68, unchanged, temp. $96^{\circ}$, resp. 20. She was depressed, complained of great pain in the back, and had frequent nausea.

On 13th September and subsequently, the normal amount of urine, sp. gr. 1013 to 1017, was passed, but there was no improvement in the symptoms.

On the 15th she vomited, but the bowels continued regular, as was always the case.

During the rest of this month and the whole of the next she grew worse, and was wholly confined to bed, being occasionally restless, fretting over imaginary troubles, and getting out of bed, and in doing so on one occasion she fell and bruised herself. She was alternately drowsy and restless with slight delirium, muttering to herself and 
being frequently under the delusion that someone was waiting for her. She complained of sick headache; the pulse was small and weak, but not accelerated; the heart sounds very feeble and hardly to be heard ; the temperature from $1^{\circ}$ to $3^{\circ}$ subnormal (see below). The urine varied from twenty to thirty-six ounces, sp. gr. 1007 to 1017, occasionally depositing a slight amount of lithates; on two or three occasions it was darker coloured and deposited phosphates. The amount of urea excreted at intervals was as follows :

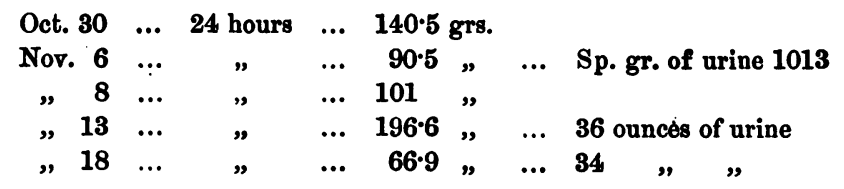

The average for the five days is $119 \cdot 1$ grains, being a reduction to about half the amount excreted by a healthy individual of her sex, size, and weight.

During the time she remained in bed and for some time after, the temperature was carefully recorded night and morning at the same hours; it was constantly subnormal from $1^{\circ}$ to $3^{\circ}$.

\begin{tabular}{|c|c|c|c|c|c|c|}
\hline verag & & & Aug. 31 to & Sept. 5-96.2 & Fahr & \\
\hline$"$ & 2nd & " & Sept. 6 to & "10-96.2 & $\eta$ & \\
\hline " & 3rd & ", & " 11 to & $\Rightarrow 15-97 \cdot 4^{\circ}$ & $"$ & \\
\hline " & 4 th & , & " 16 to & $" 20-96.9^{\circ}$ & 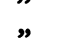 & \\
\hline " & 5 th & " & " 21 to & " $25-96 \cdot 7^{\circ}$ & " & \\
\hline " & 6th & $"$ & " 26 to & , $30-96.3^{\circ}$ & $"$ & \\
\hline " & 7th & , & Oct. 1 to & Oct. $5-95 \cdot 9^{\circ}$ & " & Constantly \\
\hline ” & 8th & , & " 6 to & $\Rightarrow 10-96.3^{\circ}$ & 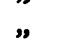 & \\
\hline " & 9th & $"$ & 11 to & $\Rightarrow 15-96.7^{\circ}$ & $"$ & \\
\hline " & 10th & , & 16 to & " $20-95 \cdot 6^{\circ}$ & ", & \\
\hline$"$ & 11th & $"$ & "21 to & $" 25-96.6^{\circ}$ & " & \\
\hline " & 12th & " & , 26 to & , $30-95 \cdot 7^{\circ}$ & $"$ & \\
\hline " & 13th & " & " 31 to & Nov. $4-96.3^{\circ}$ & ” & \\
\hline " & 14th & " & Nov. 5 to & $\Rightarrow \quad 9-966^{\circ}$ & $"$ & \\
\hline$"$ & 15th & $"$ & " 10 to & $\Rightarrow 14-95 \cdot 8$ 。 & $"$ & Began to \\
\hline " & 16th & ” & " 15 to & $\Rightarrow 19-96 \cdot 6^{\circ}$ & ” & sit up in the \\
\hline " & 17th & " & " 20 to & $\Rightarrow \quad 24-97 \cdot 7^{\circ}$ & $"$ & \\
\hline
\end{tabular}


The highest temperature recorded is $97 \cdot 7^{\circ}$, and the difference between this and the lowest was only $2^{\circ}$.

On the 7th November she was nearly relieved of the cerebral symptoms, but she still felt weak and giddy, and had a little pain in her limbs ; she walked slowly, moving the limbs equally. The pulse standing was 92 and regular, but the slightest pressure effaced it.

On the 15th of the same month she had returned very nearly to her usual state, eating and sleeping well. Five days before she left the hospital (December 12th) the catamenia reappeared after an absence of a year.

After this illness there was a marked declension of strength, but she still got up early in the morning and attended to her household duties, her condition remaining very uniform for the next two years nearly.

On the 30th September, 1881, she was again admitted into Christian Ward under my care, and died five days afterwards. She complained of loss of power in the left side so that she could not walk without help; she had a troublesome cough and a little bronchial expectoration. Her appearance and manner were unchanged, except that the expression was heavier and the speech thicker and more laboured. The skin was dry and harsh, that of the chest being rough with raised papillø. The respiration was almost entirely abdominal, 24. The breath sounds were normal on the right side excepting at the apex and down the back to the side of the vertebræ; here it was rather harsh and the expiration was prolonged. The left chest was dullish everywhere; there was an increase of vocal fremitus and bronchophony, and the breath sounds were rather tubular. The apex beat of the heart could not be either seen or felt, the first sound was inaudible, the second clear and sharp; pulse regular, small, and feeble, 72. Tongue clear and moist, appetite defective, bowels regular, the abdomen normal, the urine normal in quantity, sp. gr. 1020, free from albumin. The catamenia had been absent three months.

Left to herself she lapsed into the drowsy, semi-delirious voL. LXVII. 
state above described as her condition when in the hospital nearly two years previously. The highest temperature recorded was $97 \cdot 4^{\circ}$, but the four last days of her life it was only $94^{\circ}$. There was retention of urine the second day after admission. The day before her death she could be roused, and passed water without assistance. She died of asthenia.

The post-mortem examination was made by Dr. Gulliver. The body was well nourished, the skin singularly fair, like alabaster or œdematous tissue, but quite free from cdema excepting around the ankles, where pressure caused slight pitting. There was a moderate amount of pure white adipose tissue. The peritoneum contained a pint and a half of clear serum; here and there there were a few old fibrous adhesions, but about the uterus and ovaries they were strong and general.

The liver weighed $2 \mathrm{lb}$. $13 \frac{1}{2} \mathrm{oz}$. On the surface a few scattered yellow dots-not raised-were observable, but the structure was normal.

The kidneys weighed together $9 \frac{1}{2}$ oz.; they were lobulated, slightly elongated, and narrow. The section was unusually firm and glistening, the cortex injected, the capsule stripped off too easily, and the arteries were thickened. Otherwise the organs were quite healthy.

The uterus was nearly twice its normal size, but otherwise healthy.

The spleen, intestines, and the rest of the pelvic and abdominal viscera were normal.

The tongue was unusually firm and contracted; the thyroid gland reduced to two little yellowish-white masses, together about the size of the last joint of the little finger. The chest was narrow and the muscles pale and stringy. The pericardium was distended with clear straw-coloured serum ; there was no evidence of inflammatory action.

The heart weighed $7 \frac{1}{2}$ oz., it was firmly contracted and empty, the muscle was healthy, and the valves also, and competent; there were a few patches of commencing atheroma at the root of the aorta. 
The right pleural cavity contained half a pint of clear serum, the apex of the right lung (which weighed $1 \mathrm{lb}$. $1 \frac{1}{2}$ oz.) was firmly fixed by old adhesions; a cicatricial depression corresponded to the adhesion, and an inch internal to this there was an old nodular thickening with here and there a little cretaceous deposit. The posterior border of the lung was devoid of air and in a state of fibrous degeneration.

The left lung weighed $1 \mathrm{lb}$; ; it was everywhere firmly adherent to the chest, and behind and at the sides the pleura was converted into a thick opaque fibrous membrane, and the lung could only be separated by dissection or laceration. The whole of the lung was in a state of fibrous degeneration, being very tough, completely free from air, and sank in water. Sections presented a streaky appearance due to the paler bronchial tubes and an increase of connective tissue around them. A teaspoonful of creamy odourless pus oozed from one of the divided bronchia, and the same amount from the trachea as it was divided opposite the supra-sternal notch.

The thoracic gangliated cords were deeply implicated in the adherent and degenerated pleuræ, and on the left side the ganglia could not be satisfactorily distinguished.

My colleague, Dr. Hadden, undertook to examine the cervical sympathetic and some other of the tissues. The following is his report :- "There is no alteration which can be pronounced abnormal in the cervical sympathetic; some of the ganglion cells appeared unusually large and pigmented, but on comparison with normal specimens, I could not satisfy myself that there was much variation from the healthy condition. But on comparing these ganglia with those of another case which I have recently examined, the similarity of the changes in the two cases is very striking. The lesion consists mainly in a sclerosis causing atrophy of the fibres, leaving the cells almost unchanged. ${ }^{1}$ The changes in the skin are very marked.

1 I have examined Dr. Hadden's specimens, and adopt the first six lines of his report, but hesitate to endorse the ninth and tenth. The blood-vessels appear 
All the hairs seen in the sections are broken off short, none reaching to the surface. The fibrous layer of the hair sac is much thickened by a nucleated fibrillated tissue; the inner and outer root sheaths are obscured by a small round-celled growth, so that no normal structure can be seen. The coiled tubes which compose the sweat glands are filled with closely-packed small round cells, which become deeply stained by colouring matters; there is no lumen, and the polyhedral cells which normally line the interior are quite absent; the sudoriferous ducts near the sebaceous follicles are also blocked with similar cells; the adventitia of the small arteries seems unusually thickened. In one portion of the skin the fibrous bundles of the corium and superficial part of the subcutaneous tissue are separated one from another, but this appearance is probably artificial, for in most specimens no such condition is observable. The elastic fibres exhibit no change."

The brain and spinal cord were firm and apparently quite healthy. Apart from the morbid changes above detailed two main facts were obvious. Firstly, the quantity of blood was small; although the heart was contracted and empty, and one lung was degenerated and much less vascular than the normal organ, there was no noticeable fulness either of the superficial veins during life or of the great internal veins after death. Secondly, all the tissues were abnormally firm and tough: there was a general increase of connective tissue throughout the body. This was well illustrated in the muscles. For the purpose of the chemical examination of the tissues, the results of which are given below, I procured a new "Nye's mincing machine." It minced ordinary flesh readily and perfectly, but on trying to pass the rectus abdominis muscle of the patient through it, the knives became to be wider aud more numerous than usual. It would be interesting, of course, to find such widespread implication of the sympathetic in these cases, but I think that the symptoms in the case under consideration are sufficiently accounted for by the involvement obvious to the naked eye, of the thoracic ganglia. 
entangled in tough strings of fibrous tissue and the instrument was so much a failure that $I$ had to resort to the old plan of "the chopper and block."

Chemical Examination of the Tissues.-My object was simply to determine the amount of mucin. The process which I adopted was as follows:-One part of the tissue (15 grammes $=238$ grains) was pulped or minced and digested for a week with frequent agitation in seven parts ( 107.9 cubic centimètres $=1666$ grain measures $)$ of fresh lime-water at $60^{\circ}$ Fahr., and then filtered. The residue was then macerated in a fresh portion of lime water for from four to eight hours at a temperature gradually rising from $60^{\circ}$ to $110^{\circ} \mathrm{Fahr}$. At the end of this operation the softer tissues were completely disintegrated. The solutions were then filtered, and the mucin both of the first and second filtrate precipitated by acetic acid, collected upon a filter (associated with a second of equal weight made from the same sheet of paper), washed with water acidulated with acetic acid, and estimated in a dry crisp state. In the second maceration it is obvious that if chondrin were contained in the tissue, the amount would be included in the figures representing the amounts of mucin. But it may, I think, be assumed to be absent from all the tissues examined except the lungs. In the estimation, however, given below no artificial heat was employed, the second maceration (with heat) giving no appreciable precipitate with acetic acid.

The following is the result :

Percentage of Mucin in the following Tissues of Harriet B-.

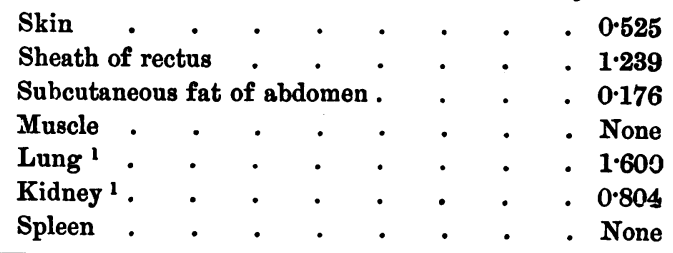

${ }^{1}$ I regret that I failed to note the parts of the organs from which the 
I am not aware that the proportions of mucin and the other constituents of healthy tissues at various ages have been ascertained, and until this has been done, the value of the foregoing data is of course unknown. As a help to myself and future inquirers, I have determined this question to some extent in respect of a woman, Eliza B-, æt. 24, who died under my care in St. Thomas's Hospital. She was the subject of mitral disease. There was slight codema of the eyes, and a little fluid in the serous cavities.

Percentage of Mucin, Albumin, and Gelatin in the following Tissues of Eliza $B-$, æt. 24.

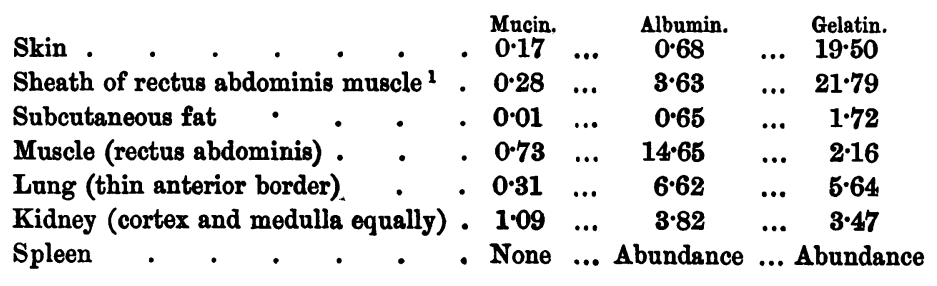

The tissues, drained of blood and finely minced or pulped, were digested in seven parts of lime-water, and subsequently in a fresh portion at a temperature ranging from $110^{\circ}$ to $160^{\circ} \mathrm{Fahr}$.; the skin and tendon requiring the higher temperature in order to effect a complete solution. Indeed, all the tissues may be at once exposed to the higher temperature, when the process may be speedily effected. I used cold lime-water at first, thinking that heat might cause some decomposition of the mucin. A carefully performed experiment on bronchial mucus proved to me that mucin in lime-water undergoes no diminution when exposed for many hours to a temperature over $160^{\circ}$ Fahr.

The process adopted was as follows:-Solution of the tissue having been effected, the filtrate was supersaturated portions analysed were taken; the significance of this (see p. 199) occurred to me subsequently.

1 The large quantity of albumin was no doubt derived from adherent muscular fibre. 
with acetic acid, precipitated mucin was collected upon a filter (placed by the side of another which served as a counterpoise, being of equal weight and equally saturated with the solution, and washed and dried together), washed, and dried. The filtrate was next treated with solution of potassium ferrocyanide so long as any precipitate formed; the albumin was collected, washed with water acidulated with acetic acid, dried, and weighed. The filtrate was lastly precipitated by freshly prepared solution of tannic acid, and the gelatine collected, washed, and dried.

In ascertaining the amount of mucin it is necessary to state the part from which the specimen was taken; for example, the cortical part of the kidney will yield less mucin than the medullary portion, and the lining membrane of the pelvis more than the medullary portion. Again, with regard to the lung, it will be obvious that the thin edge of the lung will yield less mucin than the central parts, because a portion from the latter contains larger and more numerous bronchia than the former. The quantity of albumin, too, will vary with the amount of blood retained in the tissue.

The following observation shows this :

James P-, æt. 37, died under my colleague, Dr. Stone, of enteric fever and pulmonary congestion.

\section{Percentage of Mucin, Albumin, and Gelatin.}

\begin{tabular}{|c|c|c|c|c|c|c|}
\hline Kidnev cortex & 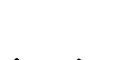 & 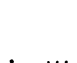 & $\begin{array}{l}\text { Mucin. } \\
0.064\end{array}$ & & $\begin{array}{c}\text { Albumin. } \\
\mathbf{4} \cdot \mathbf{3 4}\end{array}$ & $\begin{array}{c}\text { Gelatin. } \\
\mathbf{4} \cdot \mathbf{3 4}\end{array}$ \\
\hline " medulla & • & $\ldots$ & 0.64 & $\ldots$ & $4 \cdot 30$ & ... 6.19 \\
\hline Lung, diaphragr & natic edge & $\ldots$ & $0 \cdot 42$ & $\ldots$ & 0.43 & $8 \cdot 42$ \\
\hline root & . & $\ldots$ & $3 \cdot 43^{1}$ & $\ldots$ & 1.95 & ... $11 \cdot 89$ \\
\hline
\end{tabular}

Taking the two analyses together, it appears that, of those examined, the organs which yield the largest amount of mucin are the lungs and the kidneys. This was of course to be expected since the mucous membrane freely extends into both of them.

1 This large figure represents the combined amount of mucin and chondrin, by far the greater proportion being chondrin. 
Further observations will determine whether or not the quantity of mucin in the tissues of the myxœdemic patient is in excess. Compared with the analysis in the other case, the total amount is nearly double, and so far, Dr. Ord's idea of a "myxœdema" is borne out. But it appears to me that the question of an increase of mucin sinks into insignificance in face of the unmistakably great increase of the connective or fibrous tissue, and to which the increase of mucin, if this be hereafter demonstrated, may be regarded as secondary.

The morbid condition in the myxœdemic case was associated with a general increase of the fibrous tissue at the expense of the parenchyma, and hence the integumental thickening and puffiness, and the increased hardness and toughness of the tissues. Such a case as that I have described might be appropriately defined as one of "general fibrous invasion," producing a chronic, cold debility.

In this case, one lung was degenerate and useless, and as a consequence, the vital functions were proportionately reduced; the temperature was low and the urea reduced to half the normal amount. As a secondary effect, the parenchyma, adapting itself to the wants of the system, had decreased, and its place was supplied by connective tissue, which in process of time had become dense and inactive.

It remains to be considered how far the nervous system is involved in the general fibrous degeneration. In the case under consideration the cerebro-spinal system was evidently very slightly affected ; the mechanism of thought, speech, and motion were more or less impeded, and there was a slowness of each proportionate to the general debility; the intellect, however, remained unclouded, and there was an absence of paralytic symptoms. But the sympathetic system is in many of these cases more deeply involved. Since these cases have come under my notice I have always referred them to degeneration of the sympathetic centres. A case of so-called "simple 
atrophic sclerema," but really one of fibrous degeneration of the lungs and thoracic sympathetic, published by me in vol. $\mathrm{lx}$ of the 'Transactions' of the Society, is conclusive on this point; and the present case is as strong a corroboration as can well be offered. The myxcdemic and scleremic conditions in these patients were merely the consequence of severe internal inflammation experienced years before and affecting, inter alia, the pleuræ and peritoneum and the sympathetic ganglia adjacent to these membranes. It is easy to trace the effect of this, viz. a loss of tone in the blood-vessels of the connected viscera and a corresponding diminution of functional activity. The blood-vessels are the first organs to be affected by fibrous degeneration; the implication of the rest follows as a matter of course.

In the two cases to which I have just referred, fibrous degeneration of the lung was a notable factor in the disease, but it is of course conceivable that myxœdema (general fibrous invasion) or scleroderma and its allies may have their origin in inflammatory or other changes exclusively confined to the sympathetic ganglia.

If this view of the pathology of the disease be correct, myxœdema cannot be regarded as a specific disease, but merely as a variety of what I have termed "a chronic, cold debility" dependent on depression of the vital functions and frequently associated with fibroid degeneration of the lung, a condition usually, if not always, traceable to some severe antecedent illness attended by internal inflammation.

I am able to present to the notice of the Society tonight a patient of the male sex, who may be regarded as a typical example of myxœdema, and whose history and condition are strongly corroborative of the views here advocated. The following is a brief outline of the case :

George K-, æt. 52, a seaman, who has followed his profession until a few years ago. $\mathrm{He}$ is still a welldeveloped man, 5 feet $10 \frac{1}{2}$ inches high, weighing 14 stone, and well covered with fat ; circumference of chest $37 \frac{1}{2}$ 


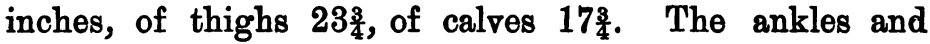
insteps are very cedematous, and there is pitting over the tibir as high as the knee, and also of the sides of the calves on making hard and prolonged pressure. For the last month the face, which before was puffy, has been distinctly œdematous around the eyes, and the integument over the upper lids hangs down as semi-transparent sacs. The lips are hard and swollen, so as to impede labiation, the voice is gruff and monotonous, and the speech slow and hesitating. The cheeks are rosy, from chronic injection of the small vessels. The thyroid gland is evidently absorbed. The skin is cold and dry, and the extremities, especially the arms and hands, are quite rough with epidermal scales; the hands and fingers are thick and clumsy and the nails incurved, those of the forefingers completely covering the end of the pulp; the hair is coarse ; the urine is normal in quantity, always free from albumin, sp. gr. 1013-1020, and acid.

He has been in the hospital under my care for the last six months, and his condition has remained unchanged, except that during the last month there has been a slight increase of œdema.

He complains of weakness and giddiness, weakness of memory, dimness of vision, and dyspnœa on the slightest exertion; his gait is slow and heavy. The pulse is 70, but very small and weak; the impulse of the heart is absent and the sounds scarcely audible, but there is absence of valvular disease; the expansion of the chest is very imperfect, there is a little dryish crepitation at the bases of the lungs; over the right upper lobe and the left upper lobe in front the expiration is audible and prolonged. The right chest is dull below the nipple line from front to back, the dulness being most marked at the side where it extends an inch above the nipple line; in every part of this lung the breath sounds are feeble, and there is marked increase of bronchophony and vocal vibration; there is neither cough nor expectoration, nor any history of previous bronchitis. His appetite is very moderate, and the 
digestion is weak; he is frequently troubled with nausea and heartburn, and has occasional attacks of vomiting, a condition very like that which was so prominent in the case of scleroderma above referred to (see p. 201). The average temperature for August and September (forty-one observations) was $97 \cdot 4^{\circ}$.

He was a remarkably strong man until 1854, when he had measles and smallpox. The latter illness occurred on board ship in the English Channel; he had no medical attention and was ill three months. Since this time he has not been strong, and subsequently he had an attack of dysentery lasting six months. Five years ago he had erysipelas of the head. He has always been subject to rheumatism of a subacute form, aching of the legs and arms. Two of his brothers have died of chronic heart and lung disease, a third of chronic lung disease, and a sister of "fits."

The patient has gradually and very slowly lapsed into his present state. He is not confined to bed, and can still walk a distance of a mile, but breathlessness is easily provoked by very moderate exertion of any kind.

During the last few weeks this patient has experienced an increase of the cedema of the legs, and the swelling of the lids almost occludes the eyeballs. He has lately suffered an attack of conjunctivitis and slight iritis of both eyes. It was doubtless of rheumatic origin. The œdema of the legs is now very great. This patient I have quite recently discovered was under Dr. Stephen Mackenzie's care in the London Hospital, and he has given an account of him in the last volume of the 'Clinical Society's Transactions' (vol. xvi, p. 260).

I have thought it would be premature to examine the few cases of myxœedema that have been published in reference to the views set forth in this paper. What appears to be needed at the present time is a full and complete history of the cases as they present themselves to us, and thus we shall acquire the facts necessary for generalisation.

One question in the pathology of myxœdema I have left 
unconsidered. It is the relation of the thyroid gland to the disease. I I have noted the atrophy of the gland in chronic lung disease, especially fibroid degeneration, and I believe that a depression of the respiratory function will be found to be the usual associate of atrophy of the thyroid; the activity of the gland being associated with increased blood-supply as in the plethora which sometimes follows the natural cessation of the catamenia; while its atrophy may be expected when, by degeneration of one half of the respiratory surface, the blood is proportionately impoverished.

1 See Dr. Stephen Mackenzie's paper, "On the Weight of the Thyroid Body," at the end of the volume. 